\title{
PENGARUH PERUBAHAN HARGA LADA TERHADAP KESEJAHTERAAN PETANI LADA KELOMPOK TANI MEGA BUANA DI DESA BATUAH KECAMATAN LOA JANAN KABUPATEN KUTAI KARTANEGARA
}

\section{THE EFFECT OF CHANGES IN THE PRICE OF PEPPER ON THE WELFARE OF PEPPER FARMERS IN MEGA BUANA GROUP IN BATUAH VILLAGE, LOA JANAN SUB-DISTRICT LOA JANAN KUTAI KABUPATEN KARTANEGARA}

\author{
Ajeng Priantari ${ }^{\star 1}$, Nur Hidayat ${ }^{1}$, Rossy Mirasari ${ }^{1}$ \\ ${ }^{1}$ Politeknik Pertanian Negeri Samarinda, Kampus Gunung Panjang, Jl. Samratulangi, \\ Samarinda, Indonesia \\ ajengpriantari20@gmail.com
}

\begin{abstract}
In Batuah Village, production of pepper has decreased due to land fires, land conversion to the mining sector and changes in other crop commodities and the price of pepper which is always changing and tends to decline. The welfare of farmers can be realized starting from increased income, increased production, and high purchase prices. The factor that causes farmers to feel less prosperous and not yet developed is that the price of pepper is bought cheaply by middlemen or collectors.

The purpose of this study was to determine the characteristics of pepper farmers and whether there is an effect of changes in pepper prices on farmer welfare. The results showed that rcount <rtabel $(-0.331<0.396)$, and it can be concluded that there is a very weak influence between the effect of price and the welfare of pepper farmers. It can be assumed that it is not only pepper plants that are planted by pepper farmers so that pepper farmers do not depend only on the commodity of the pepper plant.
\end{abstract}

Keywords: Changes in the price of pepper, Farmer Welfare

\section{PENDAHULUAN}

Indonesia adalah negara agraris dimana mempunyai kekayaan alam yang melimpah. Penyumbang ekspor di Indonesia yang merupakan suatu sektor potensial adalah komoditas lada (Kania, 2012). Produk lada yang terkenal di Indonesia yaitu lampung black papper (lada hitam) dan muntok white papper (lada putih). Lada putih paling banyak diproduksi di provinsi bangka belitung dan untuk lada hitam paling banyak di produksi di lampung. Sedangkan produksi lada di dunia paling banyak di produksi oleh negara Vietnam, Indonesia, Brazil, India dan Malaysia kelima negara ini tergabung dalam komunitas IPC (Internasional Papper Comunity). Penjualan lada tidak hanya di dalam negeri tetapi juga di luar negeri, lada sekarang dapat meningkatkan keuntungan, bahkan sekitar $85 \%$ dari hasil produksi lada di Indonesia diekspor keluar negeri. Negara-negara yang menjadi pembeli lada adalah Argentina, Australia, Algeria, Brazil, Belgia, Canada, Denmark, Jerman, Jepang, Belanda, India, Iran, Italia, RRC, Yunani dan negara eropa lainnya (Serpian, 2003).

Di provinsi Kalimantan Timur, pembudidayaan tanaman lada menyebar di 9 kabupaten/kota. Produksi lada yang terluas di Kalimantan Timur adalah di Kabupaten Kutai Kartanegara dengan luas 3.757 ha. Pemerintah melalui Dinas Perkebunan telah mengembangkan tanaman lada pada tahun 2012, dengan luas 4.231 ha (Disbun Kaltim, 2012).

Harga lada selalu berubah-ubah dan cenderung mengalami penurun pada tahun 2018 untuk harga lada hitam perkilonya seharga Rp. 57.500 sampai dengan akhir tahun 2018 mencapai Rp 37.546 dan untuk harga lada putih perkilonya dari Rp. 91.901 sampai akhir 


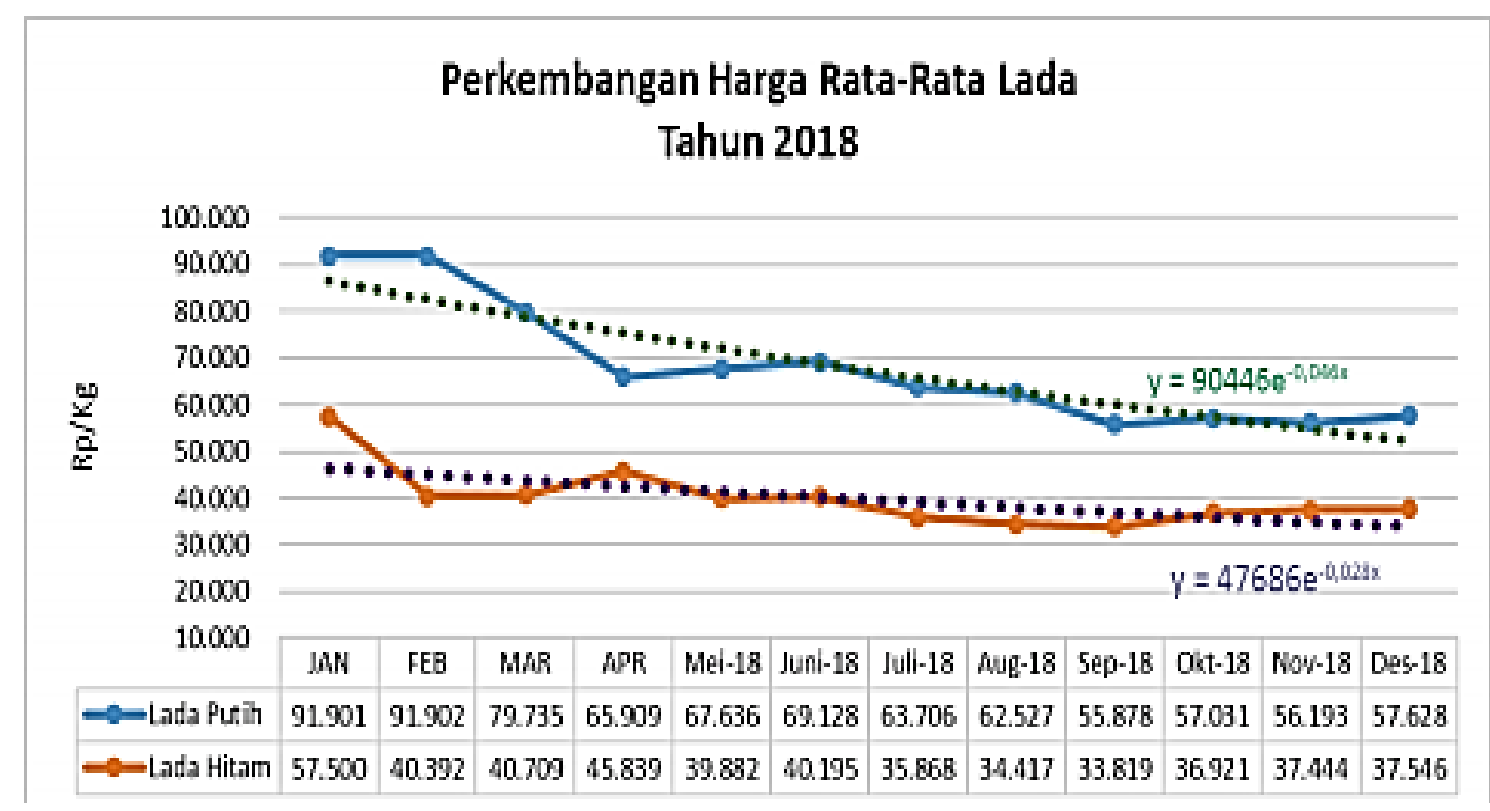

Gambar 1. Grafik Perkembangan Harga Lada Tahun 2018 (Anonim, 2019).

Desember terus berubah mencapai Rp 57.628.

Di desa Batuah produksi lada mengalami penurunan dikarenakan kebakaran lahan, alih fungsi lahan ke sektor pertambangan dan perubahan komoditi tanaman lain. Dan ada faktor lain juga yang mempengaruhi yaitu akibat kalah saing dengan lada dari luar daerah (Lampung dan Bangka) dan luar negeri (Disbun Kaltim, 2012).

Menurut Sunarti dan Khomsam (2006), petani adalah sumber daya yang penting untuk mensejahterakan masyarakat. Keberadaan petani sangat dibutuhkan bagi kehidupan manusia, tanpa bantuan petani manusia sulit untuk bertahan hidup. Kesejahteraan petani bisa diwujudkan mulai dari pendapatan yang meningkat, produksi yang meningkat, dan harga beli yang tinggi. Faktor yang menyebabkan petani masih belum bisa merasakan kesejahteraan dan belum maju adalah harga lada dibeli murah oleh tengkulak atau pengepul.

Berdasarkan uraian sebelumnya, maka dapat disusun perumusan masalah penelitian yaitu apakah yang mempengaruhi berubahnya harga lada, apakah lada termasuk komoditi yang ditanam oleh petani lada dan tak ada yang lain, apakah tingkat kesejahteraan petani lada yang ada di batuah dengan kelompok tani Mega Buana bergantung pada hasil produksi tanaman lada saja.

Penelitian ini bertujuan untuk mengetahui bagaimana karakteristik petani lada dan apakah ada pengaruh tentang perubahan harga lada terhadap kesejahteraan petani.

Agar penelitian ini dapat dilakukan lebih fokus dan berjalan dengan sempurna, maka perlu adanya batasan masalah yaitu data karakteristik petani lada yang dibatasi usia, pendidikan, lama bertani, jenis kelamin dan harga lada yang ada di desa batuah serta faktor faktor yang mempengaruhi perubahan harga lada yang menjelaskan bahwa apakah lada termasuk komoditi yang dapat mensejahterakan petani lada.

\section{METODOLOGI}

Adapun data yang diambil pada penelitian ini terdiri dari data primer dan data sekunder.

\section{Data Primer}

a. Wawancara

Wawancara merupakan pengumpulan data dengan melakukan wawancara secara langsung kepada pihak perusahaan yang bersangkutan. 
Dalam pengambilan data ini penulis mempersiapkan kuesioner yang harus di isi oleh pihak yg bersangkutan.

b. Kuesioner

Kuesioner merupakan daftar pernyataan yang digunakan untuk mempermudah

dalam pengumpulan data yang di perlukan dan di ajukan kepada responden.

c. Dokumentasi

Pengambilan gambar tentang semua kegiatan yang dilakukan di lapangan guna menunjang dalam penelitian.

\section{Data Sekunder}

Didapatkan dari sumber-sumber pustaka seperti jurnal, buku serta hasil wawancara kepada para petani sebagai data penunjang dimana bahan wawancara terlampir dilampiran dan hasil wawancaranya akan mendukung hasil penelitian peneliti.

\section{Prosedur Penelitian}

1. Persiapan alat dan bahan penelitian

2. Peninjauan Lapangan

3. Pengambilan Data

4, Pengolahan Data

\section{Teknik Pengumpulan Sempel}

Data yang dikumpulkan dalam penelitian ini adalah Data Primer dan Data Skunder.

1. Data Primer dalam pengambilan data diperoleh dari pengamatan langsung dari lapangan dan cara pengambilan sampelnya menggunakan jenis Non Probability sampling. Jenis ini tidak dipilih secara acak. Teknik Non Probability sampling yang dipilih yaitu dengan sampling jenuh (sensus) yaitu metode penarikan sampel bila semua anggota populasi dijadikan sebagai semple. Hal ini sering dilakukan apabila jumlah populasi kecil, kurang dari 30 orang (Supriyanto dan Machfudz, 2010) dan penelitian ini mengambil sempel sebanyak 25 responden.
2. Data Sekunder didapatkan dari sumber-sumber pustaka seperti jurnal, buku serta hasil wawancara kepada para petani sebagai data penunjang dimana bahan wawancara terlampir dilampiran dan hasil wawancaranya akan mendukung hasil penelitian peneliti.

\section{Teknik Analisis Data}

Kegiatan dalam analisis data adalah mengelompokan data berdasarkan variabel dan jenis responden, mentabulasi data berdasarkan variabel dari seluruh responden, menyajikan data dari setiap variabel yang diteliti. Menurut Sugiyono (2013), penilaian dilakukan dengan menggunakan skor artinya masing-masing jawaban responden diberikan nilai dengan skala pengukuran atau penilaian menggunakan metode likert, adapun skoring likert untuk masingmasing variabel adalah sebagai berikut:

a. Jika jawaban responden Sangat Tidak Setuju (STS) maka diberi skor 1

b. Jika jawaban responden Tidak Setuju (TS) maka diberi skor 2

c. Jika jawaban responden Netral (N) maka diberi skor 3

d. Jika jawaban responden Setuju (S) maka diberi skor 4

e. Jika jawaban responden Sangat Setuju (SS) maka diberi skor 5

1. Uji Validitas

Uji validitas digunakan untuk mengukur sah atau valid tidaknya suatu instrumen terhadap variabel yang diteliti. Sebuah instrumen dikatakan valid apabila mampu mengukur dan mendapatkan data dari variabel yang diteliti secara tepat. Uji validitas dalam penelitian ini adalah dengan mengkorelasikan skor item instrumen dalam suatu faktor dan mengkorelasikan skor faktor dengan skor total ( Hadi, S. 2000)

2. Kolerasi

Koefesian korelasi menurut Sugiyono (2013) yaitu melakukan penelitian dengan menghubungkan antara variabel $X$ dan $Y$ untuk 
mengetahui derajat atau kekuatan dan arah hubungan antar dua variabel.

Nilai korelasi $(r)=(-1 \leq 0 \leq 1)$. Untuk kekuatan koefesien korelasi berada di antara -1 sampai 1, dan arah ditentukan berdasarkan positif (+) dan negatif (-). Yang artinya apabila $r=-1$ korelasi negatif sempurna, artinya terjadi hubungan yang bertolak belakang antara variabel $X$ dan $Y$. Jika variabel $X$ naik maka variabel $Y$ turun. Dan $r=1$ korelasi sempurna, yang berarti terjadi hubungan yang searah antara variabel $X$ dan $Y$. Jika variabel $X$ naik maka variabel $Y$ juga naik dengan rumus.

Rumus :

$r=\frac{\mathrm{n} \sum \mathrm{XY}-\left(\sum \mathrm{X}\right)\left(\sum \mathrm{Y}\right)}{\sqrt{\left[n \sum X^{2}-\left(\sum X\right)^{2}\right]\left[n \sum Y^{2}-\left(\sum Y\right)^{2}\right]}}$

Keterangan:

$\mathrm{N}=$ Jumlah responden

$\Sigma X Y=$ Jumlah skor kuesioner $X \times Y$

$\Sigma X=$ Jumlah skor pertanyaan

(Perubahan harga)

$\Sigma Y=$ Jumlah skor pernyataan

(Kesejahteraan)

$\sum X^{2}=$ Kuardrat dari $X$

$\sum Y^{2}=$ Kuardrat dari $Y$

\section{HASIL DAN PEMBAHASAN}

\section{Hasil \\ Gambaran Umum Lokasi Penelitian}

Gambaran singkat Desa Batuah Kecamatan Loa Janan Kabupaten Kutai Kartanegara, Desa Batuah merupakan salah satu desa di Kecamatan Loa Janan, Kabupaten Kutai Kartanegara, Provinsi Kalimantan Timur, Indonesia. Dengan luas wilayah sekitar 84.7 kilometer persegi, desa ini memiliki penduduk sebanyak 8.853 jiwa yang tersebar di 10 dusun atau 49 Rukun Tetangga (RT). Desa ini dilintasi oleh jalan poros Balikpapan-Samarinda dari kilometer 15 hingga kilometer 31, dimana mayoritas penduduknya mata berpencarian petani lada, selain mata pencarian sebagai petani lada ada juga yang bermata pencarian sebagai pedagang, peternak, tanaman hias, wiraswasta dan ada juga yang menanam tanaman selain tanaman lada seperti durian, lai, buah naga, rambutan, karet dan kelapa sawit dengan jumlah petani lada di desa Batuah semuanya berjumlah 2.070 petani dan mempunyai kelompok tani sebanyak 85 kelompok yang dimana didapat dari UPTD pertanian (Unit Pelaksana Teknis Daerah) yang ada di desa batuah tersebut.

\section{Hasil Uji Validitas}

1. Validitas variabel perubahan harga $(X)$

Tabel 3. Uji Validitas Variabel Perubahan Harga (X)

\begin{tabular}{|c|c|c|c|c|c|c|}
\hline No & Pertanyaan & r hitung & Sig & $\begin{array}{c}\text { Taraf } \\
\text { signifikan }\end{array}$ & ( $r$ tabel) & $\begin{array}{c}\text { Status } \\
\text { Validitas }\end{array}$ \\
\hline 1 & $\begin{array}{l}\text { Apakah penyebab } \\
\text { turunnya harga lada ini } \\
\text { berhubungan dengan } \\
\text { kualitas panen lada }\end{array}$ & 0,429 & 0,033 & 0,05 & 0,396 & Valid \\
\hline 2 & $\begin{array}{l}\text { Apakah penyebab } \\
\text { turunnya harga lada } \\
\text { disebabkan oleh } \\
\text { kualitas dalam } \\
\text { pengolahan lada }\end{array}$ & 0,580 & 0,002 & 0,05 & 0,396 & Valid \\
\hline 3 & $\begin{array}{l}\text { Apakah penyebab } \\
\text { turunya harga lada } \\
\text { karena permintaan lada } \\
\text { yang kurang }\end{array}$ & 0,420 & 0,037 & 0,05 & 0,396 & Valid \\
\hline 4 & Apakah perubahan & 0,429 & 0,033 & 0,05 & 0,396 & Valid \\
\hline
\end{tabular}




\begin{tabular}{|c|c|c|c|c|c|c|}
\hline & $\begin{array}{l}\text { harga lada dipengaruhi } \\
\text { oleh pihak kedua, } \\
\text { ketiga dll (pengepul) }\end{array}$ & & & & & \\
\hline 5 & $\begin{array}{l}\text { Apakah penyebab } \\
\text { turunya harga lada ini } \\
\text { berhubungan dengan } \\
\text { varietas unggul }\end{array}$ & 0,611 & 0,001 & 0,05 & 0,396 & Valid \\
\hline 6 & $\begin{array}{l}\text { Apakah dengan iklim } \\
\text { yang ada varietas lada } \\
\text { yang ditanam dapat } \\
\text { menyesuaikan }\end{array}$ & 0,417 & 0,038 & 0,05 & 0,396 & Valid \\
\hline 7 & $\begin{array}{l}\text { Apakah penyebab } \\
\text { turunya harga lada ini } \\
\text { berhubungan dengan } \\
\text { iklim yang semakin tak } \\
\text { terduga }\end{array}$ & 0,439 & 0,028 & 0,05 & 0,396 & Valid \\
\hline 8 & $\begin{array}{l}\text { Apakah turunnya harga } \\
\text { lada disebabkan oleh } \\
\text { petani lada yang } \\
\text { semakin meningkat }\end{array}$ & 0,442 & 0,027 & 0,05 & 0,396 & Valid \\
\hline 9 & $\begin{array}{l}\text { Apakah penyebab } \\
\text { turunya harga lada } \\
\text { karena tak ada } \\
\text { pengeloaan lanjutan }\end{array}$ & 0,557 & 0,004 & 0,05 & 0,396 & Valid \\
\hline
\end{tabular}

Sumber : Data Olahan Hasil Penelitian 2020

Dari tabel 3 menunjukan semua pertanyaan yang digunakan untuk mengukur variabel perubahan harga $(X)$ mempunyai nilai lebih besar dari 0,05 atau taraf signifikan dimana taraf signifikan yang digunakan $5 \%$ apabila penelitian ini perhitungan validitasnya

menurun $r$ hitung $>r$ tabel maka nilai kuesioner tersebut valid dengan begitu dapat disimpulkan bahwa semua pertanyaan dari variabel perubahan harga yang diajukan mempunyai taraf signifikan yang valid.

2. Validitas Variabel Kesejahteraan ( $\mathrm{Y}$ )

Tabel 4. Uji Validitas Variabel Kesejahteraan (Y)

\begin{tabular}{|c|c|c|c|c|c|c|}
\hline No & Pertanyaan & $r$ hitung & Sig & $\begin{array}{c}\text { Taraf } \\
\text { signifikan }\end{array}$ & ( $r$ tabel) & $\begin{array}{c}\text { Status } \\
\text { Validitas }\end{array}$ \\
\hline 1 & $\begin{array}{l}\text { Dengan adanya penurunan } \\
\text { harga lada yang menurun } \\
\text { drastis hingga seperempat } \\
\text { harga masih bisa memenuhi } \\
\text { kebutuhan sehari-hari (bahan } \\
\text { pokok) }\end{array}$ & 0,578 & 0,002 & 0,05 & 0,396 & Valid \\
\hline 2 & $\begin{array}{l}\text { Apakah dengan turunya } \\
\text { harga lada secara drastis } \\
\text { dapat berpengaruh terhadap } \\
\text { pembiayaan pendidikan anak }\end{array}$ & 0,497 & 0,012 & 0,05 & 0,396 & Valid \\
\hline 3 & $\begin{array}{l}\text { Apakah dengan turunya } \\
\text { harga lada petani dapat } \\
\text { membeli sesuatu (barang } \\
\text { berharga) }\end{array}$ & 0,563 & 0,003 & 0,05 & 0,396 & Valid \\
\hline 4 & $\begin{array}{l}\text { Apakah dengan turunya } \\
\text { harga lada petani masih }\end{array}$ & 0,577 & 0,003 & 0,05 & 0,396 & Valid \\
\hline
\end{tabular}




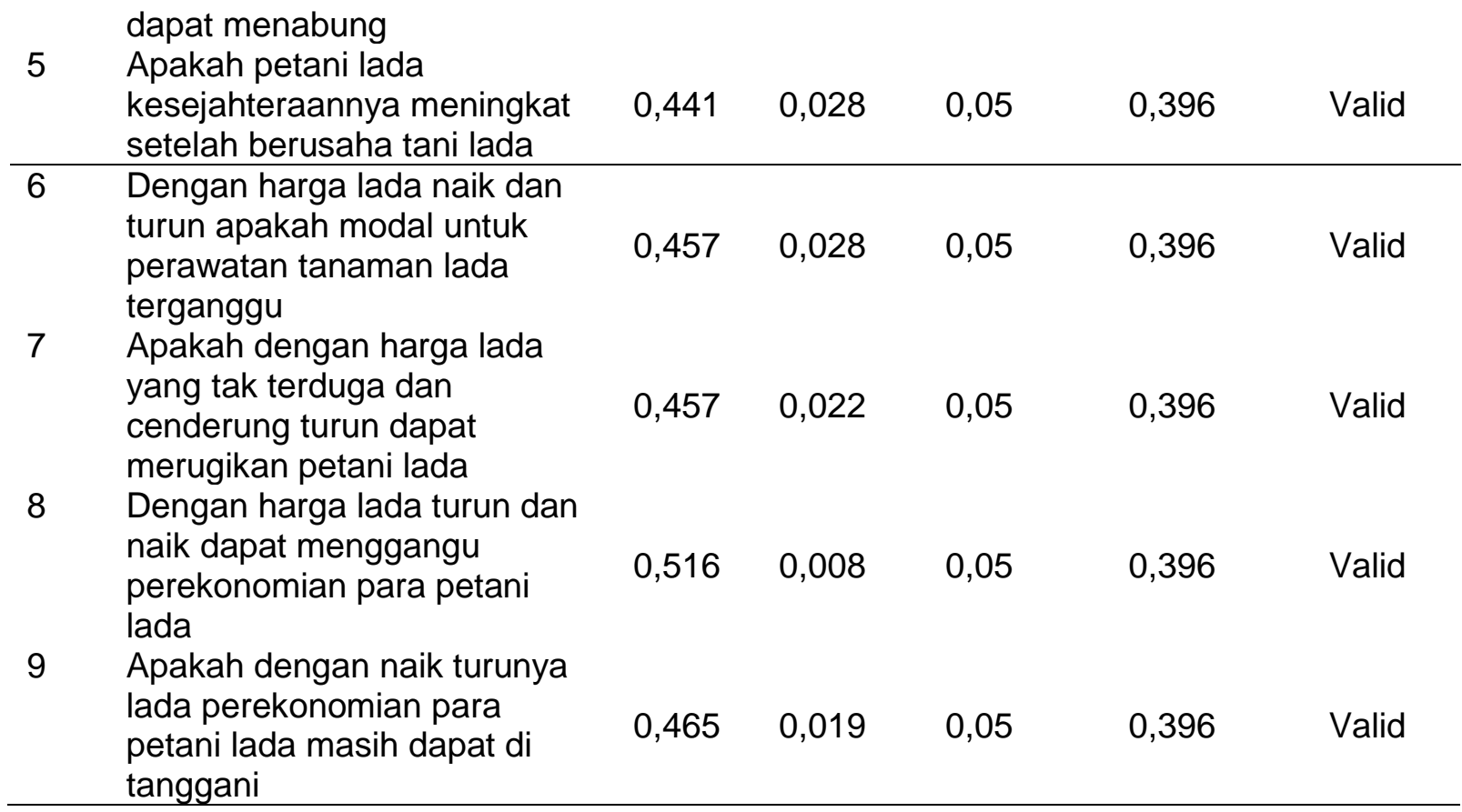

Sumber : Data Olahan Hasil Penelitian 2020

Dari tabel 4 menunjukan semua pertanyaan yang digunakan untuk mengukur variabel Kesejahteraan $(Y)$ mempunyai nilai lebih besar dari 0,05 atau taraf signifikan dimana taraf signifikan yang digunakan 5\% apabila penelitian ini perhitungan validitasnya menurun $r$ hitung $>r$ tabel maka nilai kuesioner tersebut valid dengan begitu dapat disimpulkan bahwa semua pertanyaan dari variabel kesejahteraan yang diajukan mempunyai taraf signifikan yang valid.

3. Persepsi Responden

Pernyataan-pernyataan dari responden adalah pernyataan yang dialami responden dalam keadaan responden menjadi petani lada dan kondisi sekarang yang dimana pernyataan tersebut pernyataan keluar pada saat peneliti memberikan kuesioner dan kuesionernya sebagai berikut:

1. Variabel perubahan harga $(X)$

Tabel 5. Jawaban dari Responden Terhadap Perubahan Harga

\begin{tabular}{|c|c|c|c|c|c|c|}
\hline \multirow{3}{*}{ No } & \multirow{3}{*}{ Pertanyaan } & \multicolumn{5}{|c|}{ Alternatif jawaban } \\
\hline & & STS & $\mathrm{TS}$ & $\mathrm{N}$ & $\mathrm{S}$ & SS \\
\hline & & 1 & 2 & 3 & 4 & 5 \\
\hline 1 & Apakah penyebab turunnya harga lada ini & 0 & 0 & 0 & 12 & 13 \\
\hline 2 & $\begin{array}{l}\text { Apakah penyebab turunnya harga lada } \\
\text { disebabkan oleh kwalitas dalam mengelolah } \\
\text { lada }\end{array}$ & 0 & 0 & 0 & 11 & 14 \\
\hline 3 & $\begin{array}{l}\text { Apakah penyebab turunnya harga lada karna } \\
\text { permintaan lada yang kurang }\end{array}$ & 0 & 0 & 0 & 14 & 11 \\
\hline 4 & $\begin{array}{l}\text { Apakah perubahan harga lada dipengaruhi } \\
\text { oleh pihak kedua, ketiga dll(pengumpul) }\end{array}$ & 0 & 0 & 0 & 17 & 8 \\
\hline 5 & $\begin{array}{l}\text { Apakah penyebab turunnya harga lada ini } \\
\text { berhubungan dengan varietas unggul }\end{array}$ & 0 & 9 & 16 & 0 & 0 \\
\hline 6 & $\begin{array}{l}\text { Apakah dengan iklim yang ada varietas lada } \\
\text { yang ditanam dapat menyesuaikan }\end{array}$ & 0 & 6 & 19 & 12 & 13 \\
\hline
\end{tabular}




\begin{tabular}{clccccc}
\hline 7 & $\begin{array}{l}\text { Apakah penyebab turunnya harga lada ini } \\
\text { berhubungan dengan iklim yang semakin tak } \\
\text { terduga }\end{array}$ & 0 & 0 & 0 & 18 & 7 \\
8 & $\begin{array}{l}\text { Apakah turunnya harga lada disebabkan oleh } \\
\text { petani lada yang semakin meningkat } \\
\text { Apakah penyebab turunya harga lada karena } \\
\text { tak ada pengelolaan lanjutan }\end{array}$ & 0 & 13 & 8 & 2 & 2 \\
\hline Jumlah & 0 & 0 & 10 & 15 \\
\hline Presentase & 0 & 28 & 43 & 96 & 83 \\
\hline & $2 \%$ & $2 \%$ & $4 \%$ & $33,2 \%$ \\
\hline
\end{tabular}

Sumber : Data Olahan Hasil Penelitian 2020

Berdasarkan hasil perhitungan yang peneliti lakukan, pernyataan petani terhadap kuesioner perubahan harga menghasilkan petani lada yang menjawab tidak setuju sejumlah $11,2 \%$, yang netral berjumlah $17,2 \%$, yang menjawab sangat setuju $33,2 \%$. Dapat disimpulkan bahwa presentase pertanyaan yang paling kecil berada pada posisi "tidak setuju" serta persentase yang paling besar menempati pada posisi "setuju".

menjawab setuju $38,4 \%$ dan yang

2. Variabel Kesejahteraan $(Y)$

Tabel 6. Jawaban dari Responden Terhadap Kesejahteraan (Y)

\begin{tabular}{|c|c|c|c|c|c|c|}
\hline \multirow{3}{*}{ No } & \multirow{3}{*}{ Pertanyaan } & \multicolumn{5}{|c|}{ Alternatif jawaban } \\
\hline & & STS & TS & $\mathrm{N}$ & $\mathrm{S}$ & SS \\
\hline & & 1 & 2 & 3 & 4 & 5 \\
\hline & $\begin{array}{l}\text { Dengan adanya penurunan harga } \\
\text { lada yang menurun drastis hingga }\end{array}$ & & & & & \\
\hline 1 & $\begin{array}{l}\text { seperempat harga masih bisa } \\
\text { memenuhi kebutuhan sehari-hari } \\
\text { (bahan pokok). } \\
\text { Apakah dengan turunnya harga lada }\end{array}$ & 0 & 0 & 0 & 11 & 13 \\
\hline 2 & $\begin{array}{l}\text { secara drastis dapat berpengaruh } \\
\text { terhadap pembiayaan pendidikan } \\
\text { anak }\end{array}$ & 0 & 0 & 0 & 15 & 10 \\
\hline 3 & $\begin{array}{l}\text { Apakah densgan turunnya harga lada } \\
\text { petani dapat membeli sesuatu }\end{array}$ & 0 & 12 & 10 & 3 & 0 \\
\hline & (barang berharga) & & & & & \\
\hline 4 & $\begin{array}{l}\text { Apakah dengan turunnya harga lada } \\
\text { petani masih dapat menabung }\end{array}$ & 0 & 11 & 13 & 1 & 0 \\
\hline 5 & $\begin{array}{l}\text { Apakah petani lada kesejahteraannya } \\
\text { meningkat setelah berusaha tani lada }\end{array}$ & 0 & 2 & 0 & 13 & 10 \\
\hline 6 & $\begin{array}{l}\text { Dengan harga lada naik dan turun } \\
\text { apakah modal untuk perawatan } \\
\text { tanaman lada terganggu }\end{array}$ & 0 & 0 & 1 & 13 & 11 \\
\hline 7 & $\begin{array}{l}\text { Apakah dengan harga lada yang tak } \\
\text { terduga dan cenderung turun dapat } \\
\text { merugikan petani lada }\end{array}$ & 0 & 0 & 0 & 9 & 16 \\
\hline 8 & $\begin{array}{l}\text { Dengan harga lada turun dan naik } \\
\text { dapat menggangu perekonomian para } \\
\text { petani lada }\end{array}$ & 0 & 0 & 0 & 15 & 10 \\
\hline
\end{tabular}




\begin{tabular}{cccccc}
\hline $\begin{array}{l}\text { Apakah dengan naik turunnya lada } \\
\text { perekonomian para petani lada masih } \\
\text { dapat di tanggani }\end{array}$ & 0 & 0 & 1 & 15 & 9 \\
\hline Jumlah & 0 & 25 & 25 & 95 & 79 \\
\hline Presentase (\%) & $0 \%$ & $\begin{array}{c}11,1 \\
\%\end{array}$ & $11,1 \%$ & $\begin{array}{c}42,4 \\
\%\end{array}$ & $35,2 \%$ \\
\hline
\end{tabular}

Sumber : Data Olahan Hasil Penelitian 2020

Berdasarkan hasil perhitungan yang peneliti lakukan, pernyataan petani terhadap kuesioner kesejahteraan menghasilkan petani lada yang menjawab tidak setuju sejumlah $11,1 \%$, yang netral berjumlah $11,1 \%$, yang menjawab setuju $42,4 \%$ dan yang

\section{Uji Korelasi Sederhana}

Hasil dari perhitungan analisis korelasi sederhana dapat dilihat pada tabel berikut: Tabel 7. Perhitungan Analisis Korelasi Sederhana

\begin{tabular}{cccc}
\hline Variabel & Korelasi & Signifikan & R tabel \\
\hline Perubahan Harga & $-0,331$ & 0,106 & 0,396 \\
Kesejahteraan & $-0,331$ & 0,106 & 0,396 \\
\hline
\end{tabular}

$\mathrm{HO}: \mathrm{r}=$ ( tidak terdapat signifikan)

$\mathrm{H} 1: \mathrm{r} \neq-, 0331$ ( terdapat hubungan signifikan )

Dengan adanya data diatas membuktikan bahwa $\mathrm{HO}$ ditolak sedangkan $\mathrm{H} 1$ di terima, Dari perhitungan uji pearson corralation berdasarkan total skor diperoleh $r$ hitung sebesar $-0,331$ dengan signifikan sebesar 0,106. Yang berarti nilai korelasi ( $r$ ) terdapat hubungan antara variabel perubahan harga $(\mathrm{x})$ dan kesejahteraan (y) tetapi lemah di karena kan berada di antara 0,00-0,199.

Koefesien korelasi sebesar - 0,331 dengan $r_{\text {tabel }}$ di peroleh sebesar 0,396 sehingga dapat dilihat $r_{\text {hitung }}$ lebih kecil dari $r_{\text {tabel. }}$ Hal tersebut menunjukan terdapat hubungan yang sangat lemah.

\section{Pembahasan}

Dari hasil analisis data yang dilakukan oleh peneliti saat melakukan olah data menggunakan SPSS, untuk mengetahui apakah terdapat pengaruh atau korelasi antara variabel perubahan harga lada dan variabel kesejahteraan di kelompok tani Mega Buana yang ada di Desa Batuah, Kecamatan Loa Janan, Kabupaten Kutai Kartanegara, berikut mengenai pembahasan dari hasil penelitian yang telah dilakukan. menjawab sangat setuju 35,2\%. Dapat disimpulkan bahwa presentase pertanyaan yang paling kecil berada pada posisi "tidak setuju" dan "netral" serta persentase yang paling besar menempati pada posisi "setuju". 
pengepul melainkan lada tersebut disimpan dipenyimpanan yang mereka buat sampai harga lada menjadi naik.

Salah satu cara meningkatkan produktivitas perkebunan rakyat adalah dengan mengadopsi pola tanaman polikultur (Bentley, 2004). Sistem budidaya dengan polikultur menjamin berhasilnya penanaman menghadapi iklim yang tidak menentu, serangan hama dan penyakit serta fluktuasi harga. Selain itu, polikultur sangat baik dilakukan di wilayah yang padat tenaga kerja, luas pertanian terbatas. Maka pola tanam polikultur dapat meminimalkan resiko dan memaksimalkan keuntungan (Soekirman, 2007).

Dari hasil pengamatan peneliti, saat dilapangan peneliti melihat tidak adanya petani yang tidak mempunyai rumah yang terbilang tak layak melainkan semua rumah para petani mempunyai rumah yang bagus

Dari hipotesisi peneliti saat melihat dari lapangan bahwa pendapatan yang didapatkan petani dari hasil lada berpengaruh pada tingkat pendapatan yang didapat oleh petani selain itu ada faktor-faktor yang mempengaruhi kesejahteraan petani lada seperti jumlah tanaman, pengalaman, pendidikan, umur tanaman, luas lahan. Hal ini sama seperti yang dikemukakan oleh (istiana dkk, 2015) bahwa faktor-faktor yang mempengaruhi pendapatan secara simultan dipengaruhi oleh variabel jumlah tanaman, pengalaman, pendidikan, umur, luas lahan dan jumlah tenaga kerja. Begitu juga dengan harga jual dari lada tersebut adalah suatu hal yang membuat kesejahteraan petani lada dapat meningkat seperti menurut (Phahlevi. R, 2013) bahwa Harga jual yang tinggi akan meningkatan pendapatan.

Dari hasil pembahasan di atas membuktikan bahwa pengaruh perubahan harga dapat dipengaruhi berbagai faktor tetapi hal yang dapat menggangu kestabilan usaha adalah harga yang tidak menyesuaikan dengan modal yang dikeluarkan atau keuntungan sedikit bahkan berujung tidak mendapatkan keuntungan.

\section{KESIMPULAN}

Dari hasil penelitian dan pembahasan, maka kesimpulan yang dapat diambil adalah:

1. Dari hasil pengamatan yang telah dilakukan bahwan lama bertani lada mempengaruhi keberhasilan bertani lada

2. Dari hasil uji korelasi menunjukan bahwa faktor pengaruh perubahan harga terhadap kesejahteraan pada petani lada adanya pengaruh tetapi sangat lemah, antara perubahan harga terhadap kesejahteraan petani lada

3. Dari hasil pengamatan bahwa petani lada tidak hanya mengandalkan tanaman lada yang di jadikan untuk mendapatkan pendapatan tetapi petani juga menanam tanaman lain, sehingga kesejahteraannya setabil

\section{DAFTAR PUSTAKA}

Anonim. 2019. Statistik Perkebunan Indonesia 2018 - 2020 .

Arsyad, MSc, 1999. Ekonomi Mikro. (Jakarta: Gema Press, 1999), hal 23

Basri, M,I. 2005. Islam dan Pembangunan Ekonomi. Jakarta: Gema Insani Press.

Betley WJ. 2004. Neighbor Trees: Shade. Intercropping. And Cacao in Ecuador. (Jurnal). Plenum Publishing Corporation. Human Ecology. Vol 32. No. 2. April 2004: Ecuador.

Dinas Perkebunan. 2012 Lada Kukar diminati Eropa. https: //disbun. kaltimprov. artikel/ lada kukar diminati eropa.

Departemen Pertanian. 2007. Kinerja Ekspor Impor Pertanian Indonesia Tahun 2006. www.agribisnis_deptan.

Evizal, R. 2013. Tanaman Rempah dan Fitofarmaka. Penerbit lembaga Penelitian Universitas Lampung. Bandar lampung.

Hadi S. 2000. Metodelogi Penelitian. Yogyakarta: Andi Yogyakarta.

Hapsoh dan Hasnah, 2011. Budidaya tanaman obat dan rempah. Medan: USU Press. 
Istiana dkk. 2015. "Faktor-Faktor yang Mempengaruhi Tingkat

Pendapatan Petani Kopi (Coffea

sp) Di Kecamatan Jambu Kabupaten Semarang"

Kania, R. 2012. 'Analisis Daya Saing Ekspor Lada Indonesia di Pasar Internasional'. Universitas Siliwangi, Tasikmalaya

Muhson, A. 2015. Pedoman Pratikum Aplikasi Komputer Lanjut. Yogyakarta : FE UNY.

Phahlevi. R, 2013. "Faktor-Faktor yang Mempengaruhi Pendapatan

Petani Padi Sawah di Kota Padang : Universitas Negeri Padang".

Rismunandar. 2003. Usahatani Lada Perdu. Kanisius. Yogyakarta.

Sarpian, 2003. Pedoman Berkebun Lada dan Usaha Tani.Yogyakarta: Kanisius. Terhadap Pengembangan Lada Nasional. Disertasi. Pascasarjana Institut Pertanian Bogor. Bogor.

Siregar Syofiyan, 2017. Statistik Parametrik untuk Penelitian Kuantitatif. Jakarta: Bumi Aksara.

Sunarti dan Khomsan, 2006. Kesejahteraan keluarga petani mengapa sulit diwujudkan. Institut Pertanian Bogor. Bogor

Sugiyono, 2010.Statistika Untuk Penelitian. Bandung: Alfabeta .2013. Metode Penelitian Kuantitatif, Kualitatif dan R\&D. Bandung : Alfabeta.CV

Supriyanto dan Machfudz, 2010. Metologi Riset Manajemen Sumber Daya Manusia. Malang Press. HIm. 2

Soekirman. 2007. Sayum Sabah Potret Pertanian Polikultur. Medan (ID): BITRA Indonesia.

Swastha, Basu dan Irawan. 2005, Manajemen Pemasaran Modern, Liberty, Yogyakarta. 